\title{
Factors of imagery and event recall
}

\author{
CHERYL LORENZ \\ Cornell University, Ithaca, New York \\ and \\ ULRIC NEISSER \\ Emory University, Atlanta, Georgia
}

\begin{abstract}
The relationships among various measures of mental imagery and childhood memory were examined using factor analysis and other correlational procedures. Forty-six subjects completed nine mental imagery measures (Marks's VVIQ, Gordon's Vividness Scale Forms 1 and 2, Space Relations Form of the Differential Aptitude Test, Barratt's Visualization Forms A and B, Betts's QMI, Cut the Cube Task, and Richardson's VVQ), a number of memory measures, and two measures of the observer/field "point-of-view" distinction. Analysis revealed three distinct imagery factors, "vividness and control," "spatial manipulation," and "spontaneous elaboration," as well as a fourth "childhood memory" factor. Childhood memory was not significantly correlated with any imagery variables, but observer perspectives were associated more often with childhood memories than with recent memories. In addition, the tendency to recall events from the field perspective was correlated with the spatial manipulation factor.
\end{abstract}

Factor-analytic studies of mental imagery suggest that there are two more or less independent imagery traits: an ability to succeed on objective tasks that require spatial visualization, and a readiness to describe one's own experienced images as clear or vivid (DiVesta, Ingersoll, \& Sunshine, 1971; Garro, 1982; Paivio, 1971; Richardson, 1977a). The spatial factor is represented by such tasks as the Space Relations Form of the Differential Aptitude Test (Bennett, Seashore, \& Wesman, 1947) and the Minnesota Paper Form Board (Likert \& Quasha, 1948). The vividness factor is represented by self-report measures, such as Betts's Questionnaire Upon Mental Imagery (QMI; Sheehan, 1967) and Marks's (1973) Vividness of Visual Imagery Questionnaire (VVIQ). Recently, Slee (1980) suggested the existence of another dimension of individual differences, which she calls "visual elaboration." Her Visual Elaboration Scale (VES) measures the tendency to visualize details of the appearance of an object (as distinct from its identity or meaning) even when no specific task requires it. A study by Garro (1982) found visual elaboration emerging as a third imagery factor, represented not only by Slee's VES but by other variables as well.

Although it often has been suggested that mental images are related to memory processes, none of these imagery measures actually deal with episodic memory. The images required by the measures almost never represent specific experiences from the subject's own life. Spatial

This research was conducted in the psychological laboratories of Cornell University. We are indebted to Patrick Rooney for his assistance in data collection and analysis. Requests for reprints should be sent either to Cheryl Lorenz, Department of Psychology, Cornell University, Ithaca, NY 14853, or to Ulric Neisser, Department of Psychology, Emory University, Atlanta, GA 30322 tasks may require the manipulation of imagined objects, but the objects themselves are arbitrary and unfamiliar. Self-report measures often ask the subjects to form images that include a person or object, but they do not require recall of any particular past situation in which that object was present. To visualize "a car standing in the road in front of a house," as required by Gordon's (1949) Test of Imagery Control, is very different from recalling an image of one's own car as it stood in front of one's own house this morning. To imagine "the sun sinking slowly behind the horizon" in the Betts test (Sheehan, 1967) is not necessarily to remember any particular sunset. Nevertheless, many people report that recall of their own experiences is regularly accompanied by images; the relationship between imagery and memory seems well worth exploring.

Although little is known about this relationship, a few correlations have been reported in the literature. Karis (1980) found that high scorers on Slee's VES had much more accessible memories of early childhood than did low scorers. The number of times a subject failed to recall an early memory on cue, for example, was correlated -.54 with VES scores. In addition, the same memory measures correlated -.52 with the Gordon scale and -.50 with Marks's VVIQ. Garro (1982) also has reported a significant correlation between measures of visual elaboration and the accessibility of childhood memory.

Recent work by Nigro and Neisser (1983) has suggested another angle from which to explore the relationship between imagery and memory. They investigated a dimension of memory which they refer to as "Point of View." In certain memories, one seems to "see oneself" from the outside, as an observer would; in others, one recaptures something more like his/her original field of view. 
Some individuals seem to have mostly field memories, and others have mostly observer memories, but there have been no studies of the relationship between this variable and measures of imagery ability. Moreover, the observer/ field distinction may be especially important in connection with early recollections. Henri and Henri (1896) reported that the earliest childhood memories in their study usually included an observer perspective. However, there have been no systematic studies of the relationship in this century.

The present investigations, based on factor analysis and other correlational methods, had several goals. First, we hoped to replicate and confirm the factor structures found in previous research. We were especially interested in whether visual elaboration would emerge as a separate factor in our study, as it had for Garro (1982). Although our test battery did not include the measure with the highest loading on Garros's elaboration factor (Slee's VES itself, which must be administered individually), we did include the three measures with the next highest loadings: the Gordon (1949) test, Richardson's (1977b) VerbalizerVisualizer Questionnaire (VVQ), and Bennett et al.'s (1947) Space Relations test.

A second aim of our study was to explore the relationship between imagery and reported early memory described by Karis (1980) and by Garro (1982). With this in mind, we included in our test battery several requests for early childhood recollections. We also included questions about more recent (adult) memories, with a view to exploring the links between imagery and episodic memory in a more general way. In addition, we included several questions about remembered dreams, to find whether dream recall would be related to any of the imagery variables. Finally, we hoped to examine the relationships between the observer/field distinction in memory and the other variables in our study.

\section{METHOD}

\section{Subjects}

Fifty-eight Cornell students (38 females, 20 males) were recruited through sign-up sheets that were distributed in classrooms and posted in hallways. Subjects ranged in age from 17.8 to 20.5 years. Each subject received a payment of $\$ 5$ upon completion of all tasks. Two male subjects were eliminated because they did not complete the second session. Data from 10 other subjects included missing values; these subjects were eliminated from the factor analyses, resulting in a $74 \%$ female sample.

\section{Materials}

The 13 tasks completed by each subject are described below in their order of presentation.

Marks's Vividness of Visual Imagery Questionnaire (VVIQ). The VVIQ is a 16-item scale in which subjects are asked to form visual images of various scenes, such as "the sun rising above the horizon into a hazy sky" (Marks, 1973). Each image is rated on a 7-point scale, ranging from "The image is perfectly clear, and as vivid as the actual experience" (rating of 7) to "No image is present at all, although you are thinking about the object" (rating of 1). This test has a reported test-retest reliability of .74 (Marks, 1973).

Gordon's Imagery-control Scale, Form I. This is a revised version of a scale first developed by Gordon in 1949 (Richardson,
1969). It consists of 12 items concerned with the manipulation of visual images. Subjects are first asked to form an image of a car and then asked to "see" it change color, location, or position. Subjects respond "Yes" ( 2 points), "No" (0 points), or "Unsure" ( 1 point) to indicate whether they have succeeded in visualizing the altered scene. Reported reliability coefficients range from .76 to 95 (Juhasz, 1972; McKelvie \& Gringras, 1974).

Space Relations Form, Differential Aptitude Test (DAT). The DAT is a 60 -item test; each item shows an "unfolded" threedimensional figure and four alternatives for its correct shape when folded (Bennett, Seashore, \& Wesman, 1947). Our subjects worked on the DAT (Form $\mathrm{T}$ ) for $20 \mathrm{~min}$.

Barratt's Visualization Form. On this questionnaire (Barratt, 1953), subjects rate their use of visualization while solving the problems of the previously completed DAT. They rate the strength and clearness of the images they formed, the importance of visualization in solving the DAT problems, and their facility in manipulating those images. Each rating is made on a 7-point scale, with 7 indicating strong use of imagery.

List of Early Memories (LEM). In this task, subjects were given 5 min to recall as many events as possible from before they were 6 years old. They were asked to list only things they remembered themselves, not occasions they remembered from being told about them or from looking at old photos. A single line was provided for each memory. In each case, they were also asked to estimate their age at the time

Early Memories Observer/Field Ratings. Subjects were asked to identify the "point of view" from which they remembered the childhood memories that they had just recalled. The following categories (Nigro \& Neisser, 1983) were provided:

(O) In your memory, you imagined the scene as an observer might see it. Such an observer would see you as well as other aspects of the situation

(F) In your memory, you imagined the scene from your original point of view, not as an external observer would see it. (N) Neither of the above perspectives seems to describe the way you remembered the situation.

These data are not included in the main factor analysis.

Betts's Questionnaire Upon Mental Imagery (QMI). This 35item questionnaire is a shortened version of Betts's original form (Sheehan, 1967). Subjects are asked to imagine five instances from each of the following categories: visual, auditory, cutaneous, kinesthetic, gustatory, olfactory, and organic. For example, a kinesthetic item asks subjects to "consider carefully the image which comes to your mind's arms, legs, lips, etc." when thinking about "reaching up to a high shelf." The 5 items for each modality are grouped together. Subjects rate their images on a 7-point rating scale like that of the VVIQ. A test-retest reliability (7-month interval) of .76 (Sheehan, 1967) and a split half reliability of .95 (Juhasz, 1972) have been reported.

Gordon's Vividness Scale, Form II. This revised version of Gordon's scale was created by the present authors. The items are essentially identical to those of the original form, except that a snowmobile replaces the car. The rating scale remained the same.

Cube Task. The following instructions for this traditional im agery task were read aloud to the subjects, who also had a written text.

Imagine a cube $3 \times 3 \times 3$ in. and painted red all over. Now imagine that it has been cut into 27 smaller cubes, each $1 \times 1 \times 1$ in., by making two equidistant horizontal cuts, two equidistant vertical cuts, and two equidistant lateral cuts. When you think you understand the description, please turn the page and answer the questions there.

These instructions were modified from those reported by Richard son (1977a) and by Garro (1982). (Their instructions apparently directed subjects to make only four cuts through the cube, which 
would result in nine rectangular solids $1 \times 1 \times 3$ in.) Subjects were asked not to draw pictures or to use their fingers to count while completing this task. On the second page, we asked questions about how many of the small cubes had four, three, two, one, and zero red sides.

Barratt's Visualization Form. Another copy of the form, identical to the one that had been completed after the DAT, was presented to the subjects. This time they answered it with reference to their use of visualization on the preceding Cube Task.

Recalled-Event Description. Subjects were asked to recall some specific occasions, being careful to describe only things that they actually remembered themselves: they were not to mention anything that they remembered only because someone had told them about it, or that "must have occurred" in a specific way. They were asked to describe the following six occasions: (1) January 1, 1983 (about 5 months before our study); (2) the day President Reagan was shot (about 2 years earlier); (3) their first day of school (either first grade or kindergarten); (4) the first manned landing on the moon (which occurred in 1969 when our subjects were young children); (5) their earliest memory; and (6) a dream they had last week. Approximately one quarter of a page was provided for each memory. Data obtained from the dream memory, which was collected for exploratory purposes, were not included in the main analyses.

Recalled-Event Description, Observer/Field Ratings. Utilizing the same categories as before, $(\mathrm{O}, \mathrm{F}$, and $\mathrm{N})$, subjects rated each of the six memories just described. These data are not included in the factor analyses.

Richardson's Verbalizer-Visualizer Questionnaire (VVQ). This form consists of 15 true/false questions concerning the subjects' everyday use of words and images, such as "I cannot generate a mental picture of a friend's face" (Richardson, 1977b). Only the 8 questions concerning visualizations were included in our analysis. Ratings of 1 for utilizing imagery and 0 for not utilizing imagery were assigned. Richardson (1977) reports a test-retest reliability (7-day interval) of .91 .

\section{Procedure}

Whenever possible, subjects completed the tasks in groups; however, some individuals were tested alone. The first six tasks were completed during the first hour-long evening session, after which another experimenter spent 30 min administering a visual imagery experiment to the subjects. The last seven tasks were completed in a second hour-long evening session during the same week. All subjects were tested during April and May of 1983. A brief introduction was given before the first task. Subjects were told that there were no right or wrong answers for most of the tasks. They were encouraged to ask questions at any time. Instructions for each new task were read aloud, so all group members began each task at the same time. Except for the DAT and the List of Early Memories, the tasks had no time limits. Individuals were permitted to read or write at their seats if they completed a given task before the other subjects.

\section{ANALYSIS}

The results obtained in 11 of the tasks (excluding observer/field and dream measures) were used to define the following 15 variables. Basic statistics for these variables are reported in Table 1.

(1) QMI: The mean of the 35 item ratings on the Betts QMI was the subject's score [Correlations between vividness in the different modalities ranged from .22 (organic and olfactory) to .65 (cutaneous and gustatory).] Possible scores ranged from 1 to 7 .

(2) Barratt: The two Barratt forms were combined, and the mean of all six items was computed to obtain the sub-
Table 1

Basic Statistics for Variables in Factor Analyses

\begin{tabular}{lrrrrr}
\hline \multicolumn{1}{c}{ Variables } & $\mathrm{n}$ & Mean & \multicolumn{1}{c}{ SD } & Min & Max \\
\hline QMI & 56 & 5.4 & 0.70 & 3.8 & 6.8 \\
Barratt & 56 & 5.3 & 0.94 & 3.3 & 7.0 \\
Gordon & 56 & 19.6 & 3.90 & 10.0 & 24.0 \\
VVIQ & 56 & 5.3 & 0.86 & 1.9 & 6.8 \\
VVQ & 56 & 4.0 & 1.04 & 1.0 & 5.0 \\
DAT & 56 & 36.4 & 9.49 & 15.0 & 54.0 \\
Cube & 56 & 3.6 & 1.43 & 1.0 & 5.0 \\
January 1 & 56 & 3.5 & 1.56 & 0.0 & 6.0 \\
Reagan & 56 & 3.7 & 1.90 & 0.0 & 7.0 \\
School & 56 & 1.7 & 1.61 & 0.0 & 5.0 \\
Moon & 56 & 1.8 & 1.63 & 0.0 & 6.0 \\
Earliest Memory & 56 & 35.3 & 22.35 & 3.0 & 98.0 \\
Earliest Age & 52 & 3.5 & 1.70 & 1.0 & 9.0 \\
Memory Number & 56 & 10.5 & 4.46 & 3.0 & 24.0 \\
Mean age & 49 & 4.4 & 0.68 & 2.8 & 6.0 \\
Dreams Remembered & 56 & 2.4 & 1.94 & 0.0 & 7.0 \\
Current Dreams & 56 & 1.2 & 1.29 & 0.0 & 5.0 \\
Dream Words & 56 & 33.1 & 37.48 & 0.0 & 140.0 \\
\hline
\end{tabular}

ject's score. (The correlation between the two forms was

.57.) The possible range of scores was from 1 to 7 .

(3) Gordon: Sums were computed for each form of the Gordon task, and the mean of these two values was the subject's score. Possible scores ranged from 0 to 24 . Scores for 3 subjects who reported never having seen snowmobiles were based on the car form only. Cronbach's alphas for Forms I and II were .72 and .83, respectively; the correlation between them was $.73(n=53)$.

(4) VVIQ: The mean of the 16 item ratings was the subject's score. Cronbach's alpha was .89. Possible scores ranged from 1 to 7 .

(5) $V V Q$ : The sum of the eight visual questions was the subject's score, so the possible range of scores was $0-8$.

(6) DAT: The score was simply the number correct; the highest possible score was 60 .

(7) Cube Task: The number of correct answers out of five questions was the subject's score.

The next six variables were computed from the Recalled-Event Description task. Recollections of the first four occasions described in this task, (January 1, 1983; the day President Reagan was shot; the subject's first day of school; and the first manned landing on the moon), were coded in terms of "canonical categories" like those described by Brown and Kulik (1977). The categories were defined separately for each situation. Some of them are identical to those used by Brown and Kulik ("own affect" and "other's affect"), and others followed from the activity being described ("going to school" and "landing on moon"). One important additional category was "cognitive activity": what the subject was thinking about at the time ("I thought it was a joke" or "I wondered who had done it"). The number of categories mentioned in a subject's written description was the score for that item. The following categories were established as the basis for scoring subjects' recalls of the events:

(8) January 1: connection with New Year's Eve, daytime, meals, waking up, location, physical condition, own affect, other's affect, cognitive activity (maximum score: 9). 
(9) Reagan Shooting: source of news, companions, prior activities, post activities, location, own affect, other's affect, cognitive activity (maximum score: 8 ).

(10) School: clothing worn, going to school, arriving at school and leaving parent, going home, after-school activities, own affect, other's affect, cognitive activity (maximum score: 8).

(11) Moon Landing: location, companions, landing on moon, walking on moon, time of day, own affect, other's affect, cognitive activity (maximum score: 8 ).

Subjects who did not remember a situation at all received a score of zero. All coding was completed by the first author $(C L)$. To assess the reliability of the coding procedure, 4 subjects' descriptions were also coded by two other individuals. The correlations between CL's and the other coders' ratings ranged from .81 to 1.0 .

(12) Earliest Memory: Recall of subjects' earliest memories could not be coded into categories due to the great variety of information. The number of words written was used as a measure of the amount of recall.

(13) Earliest Age: The age in years of the subject at the time of his/her earliest memory was recorded.

Finally, two variables were computed from the List of Early Memories:

(14) Memory Number: The number of memories listed was used as a measure of the extent of the subject's memory of childhood.

(15) Mean Age: The mean age in years of the subject at the time of the listed memories was computed.

\section{RESULTS}

\section{Basic Analysis}

A correlation matrix for the 15 variables based on the data from the 46 subjects who completed all items appears in Table 2. Inspection of the pattern of significant correlations suggests that three factors were present.
Principal components analysis was used to extract three factors. Varimax rotation converged in five iterations. Variables with loadings greater than $.50(25 \%$ of the variance of the variable associated with that factor) were used to interpret the factors (Thorndike, 1978) and are indicated with an asterisk in the rotated factor matrix, which is reproduced in Table 3. Examination of these loadings suggests the following labels for the factors: Factor 1, vividness and control; Factor 2, spatial manipulation; and Factor 3 , childhood memory.

The variables that load on the vividness and control factor are all self-report imagery measures: QMI, Gordon, and VVIQ. Two of the variables that load on the spatial manipulation factor (Cube and DAT) are direct measures of spatial ability, while Barratt is a self-report measure of the use of imagery in carrying them out. The four variables that load on the childhood memory factor are Mean Age, Earliest Age, School, and Moon. The first two of these are the ages from which subjects reported childhood memories, and the other two are measures of the quality of the memories reported. No imagery measures load on the childhood memory factor. Five of the variables (January 1, Reagan, Earliest Memory, Memory Number, and VVQ) have no loadings greater than .50 and cannot be assigned to any of the three factors.

\section{Imagery Variables Analysis}

Because the childhood memory variables loaded on a separate factor, distinct from the mental imagery measures, we undertook a separate principal component analysis of the imagery variables alone. This procedure was intended to provide a cleaner picture of the relationships among the imagery measures themselves, and to test for the presence of the elaboration factor isolated by Garro (1982), which had not appeared in the first analysis. Three factors were extracted and rotated to Varimax criterion. The rotated factor matrix is reproduced in Table 4. Load-

Table 2

Correlation Matrix Used in the Principal Components Analysis

\begin{tabular}{|c|c|c|c|c|c|c|c|c|c|c|c|c|c|c|c|}
\hline & 1 & 2 & 3 & 4 & 5 & 6 & 7 & 8 & 9 & 10 & 11 & 12 & 13 & 14 & 15 \\
\hline 1. QMI & 1.0 & & & & & & & & & & & & & & \\
\hline 2. Barratt & .148 & 1.0 & & & & & & & & & & & & & \\
\hline 3. Gordon & $.559 \dagger$ & .264 & 1.0 & & & & & & & & & & & & \\
\hline 4. VVIQ & .434† & .150 & $.431 \dagger$ & 1.0 & & & & & & & & & & & \\
\hline 5. VVQ & .178 & $.592 \dagger$ & .238 & .170 & 1.0 & & & & & & & & & & \\
\hline 6. DAT & -.159 & $.393^{*}$ & .041 & .032 & .134 & 1.0 & & & & & & & & & \\
\hline 7. Cube & -.102 & $.604 \dagger$ & .229 & .106 & .208 & $.530 \dagger$ & 1.0 & & & & & & & & \\
\hline 8. January 1 & .190 & -.070 & .246 & -.046 & .036 & -.221 & -.329 & 1.0 & & & & & & & \\
\hline 9. Reagan & -.033 & -.015 & -.232 & -.183 & -.002 & -.003 & -.146 & -.168 & 1.0 & & & & & & \\
\hline 10. School & .202 & -.026 & .240 & -.080 & .065 & .008 & -.058 & .217 & -.117 & 1.0 & & & & & \\
\hline 11. Moon & -.072 & -.042 & -.028 & -.084 & -.162 & .256 & .110 & -.135 & .009 & .269 & 1.0 & & & & \\
\hline $\begin{array}{l}\text { 12. Earliest } \\
\text { Memory }\end{array}$ & .131 & .139 & -.011 & .110 & -.061 & -.030 & .074 & .198 & -.024 & .032 & -.008 & 1.0 & & & \\
\hline $\begin{array}{l}\text { 13. Earliest } \\
\text { Age }\end{array}$ & .084 & .257 & .019 & .194 & .134 & -.204 & -.001 & .158 & -.016 & -.276 & -.287 & .258 & 1.0 & & \\
\hline $\begin{array}{l}\text { 14. Memory } \\
\text { Number }\end{array}$ & .174 & .254 & .240 & .051 & .202 & .169 & .048 & -.024 & -.087 & .116 & .188 & -.066 & -.124 & 1.0 & \\
\hline $\begin{array}{l}\text { 15. Mean } \\
\text { Age }\end{array}$ & -.272 & -.122 & -.119 & .128 & -.119 & -.224 & -.064 & .026 & .046 & $-.468 \dagger$ & -.304 & -.048 & $.497 \dagger$ & -.221 & 1.0 \\
\hline
\end{tabular}


Table 3

Rotated Factor Matrix

\begin{tabular}{|c|c|c|c|c|}
\hline & $\begin{array}{c}\text { FACTOR } 1 \\
\text { Vividness } \\
\text { \& Control }\end{array}$ & $\begin{array}{c}\text { FACTOR } 2 \\
\text { Spatial } \\
\text { Manipulation }\end{array}$ & $\begin{array}{l}\text { FACTOR } 3 \\
\text { Childhood } \\
\text { Memory }\end{array}$ & $h^{2}$ \\
\hline QMI & $.78429 *$ & -.08823 & -.10613 & .63415 \\
\hline Gordon & $.77215^{*}$ & .16813 & -.12659 & .64051 \\
\hline VVIQ & $.55597 *$ & .17703 & .23839 & .39727 \\
\hline Cube & -.01438 & $.83338^{*}$ & -.01749 & .69503 \\
\hline Barratt & .32241 & $.80216^{*}$ & .10740 & .75894 \\
\hline DAT & -.16958 & $.70669 *$ & -.28979 & .61214 \\
\hline Mean Age & -.17675 & -.10232 & $.78382 *$ & .65609 \\
\hline Earliest Age & .24243 & .05218 & $.75312^{*}$ & .62868 \\
\hline School & .32305 & -.16291 & $-.65203^{*}$ & .55604 \\
\hline Moon & -.17570 & .11781 & $-.60361^{*}$ & .40909 \\
\hline January 1 & .47390 & -.43865 & .04211 & .41877 \\
\hline Reagan & -.30930 & -.02156 & .06611 & .10050 \\
\hline $\begin{array}{l}\text { Earliest } \\
\text { Memory }\end{array}$ & .23820 & -.00472 & .16154 & .08285 \\
\hline VVQ & .40093 & .49037 & .08020 & .40763 \\
\hline $\begin{array}{l}\text { Memory } \\
\text { Number }\end{array}$ & .26825 & .26223 & -.34787 & .26173 \\
\hline Variance & 2.4883 & 2.4605 & 2.3107 & \\
\hline
\end{tabular}

*Loadings greater than .50 were used to interpret the factors.

Table 4

Principal Components Analysis of Imagery Variables

\begin{tabular}{lcccc}
\hline & $\begin{array}{c}\text { FACTOR 1 } \\
\text { Vividness } \\
\text { \& Control }\end{array}$ & $\begin{array}{c}\text { FACTOR 2 } \\
\text { Spatial } \\
\text { Manipulation }\end{array}$ & $\begin{array}{c}\text { FACTOR 3 } \\
\text { Spontaneous } \\
\text { Elaboration }\end{array}$ & $\mathrm{h}^{2}$ \\
\hline Gordon & $.813^{*}$ & .135 & .155 & .703 \\
QMI & $.808^{*}$ & -.246 & .167 & .741 \\
VVIQ & $.776^{*}$ & .105 & -.014 & .614 \\
Cube & .083 & $.855^{*}$ & .221 & .786 \\
DAT & -.055 & $.851^{*}$ & .037 & .728 \\
Barratt & .148 & $.518^{*}$ & $.736^{*}$ & .832 \\
VVQ & .117 & .032 & $.931^{*}$ & .881 \\
Variance & 1.950 & 1.083 & 1.510 & \\
\hline
\end{tabular}

*Loadings greater than .50 were used 10 interpret the factors.

ings greater than .50 were again used to interpret the factors and are indicated with an asterisk.

The first two of the extracted factors are very similar to Factors 1 and 2 discussed above and are similarly labeled. Factor 3, however, is new. Only two measures, Barratt and VVQ, load highly on it. For both of these measures, subjects were requested to describe their spontaneous use of imagery, either on a spatial test or in daily life. These tasks did not explicitly demand the use of imagery; rather subjects were asked after the fact whether they used it or not. In this respect, they resemble Slee's (1980) Visual Elaboration Scale. This third factor, labeled "spontaneous elaboration," appears similar to Garro's (1982) elaboration factor.

\section{Dream Variables Analysis}

An exploratory analysis was performed in order to examine the relationship of memory for dreams to the other measures in this study. The following three dream variables were considered: the number of times per week at least one dream is remembered (dreams remembered), the number of dreams currently remembered from last week (current dreams), and the number of words in the written description of a dream from last week (dream words). Basic statistics for these variables are included in Table 1. Inclusion of these variables resulted in a $18 \times 18$ correlation matrix, from which four factors were extracted using principal components analysis. Again, these factors were rotated to Varimax criterion. The only variables with loadings greater than .50 on the first factor were the three dream variables. These variables had no loadings greater than 17 on any of the other three factors. Thus, dream reports constitute an essentially separate factor, unrelated to the imagery or memory measures. We will not consider them further in this paper.

\section{The Observer/Field Distinction: Recent Versus Childhood Memories}

Additional analyses were conducted to examine the relationships between the observer/field "point-of-view" distinction in memory and the other variables. The distributions of observer and field ratings for the five memories (excluding dreams) of the Recalled-Event Description appear in Table 5. Two points should be noted here. First, more field than observer memories were reported in four of the five situations. Second, this difference does not appear to be as great for childhood memories as for recent ones. Since the data in Table 5 do not permit tests of significance, we computed the following two indices for each subject: (1) the proportion of reported childhood memories (School, Moon, and Earliest Memory) described as "observer" and (2) the proportion of reported recent memories (Reagan and January 1) described as "observer." Twenty-seven of 56 subjects showed no difference between these proportions, but a striking trend appeared in the 29 who did: The proportion of "observer" reports was higher among childhood than recent memories for 20 subjects, lower in only 9 . A two-tailed binomial test of the difference between $20 / 29$ and $9 / 29$ gives a significance level of $p<.06$ for this tendency to report a greater proportion of observer memories from childhood.

\section{The Observer/Field Distinction: Correlates}

Two "field ratios" were defined as measures of each subject's tendency to recall events from the field perspec-

Table 5

Distribution of Observer and Field Ratings for Recalled Event Description Memories

\begin{tabular}{lcccc}
\hline & \multicolumn{3}{c}{ Rating } & \\
\cline { 2 - 4 } & Observer & Field & Neither & No Memory \\
\cline { 1 - 1 } Recent Memories & & & & \\
\cline { 1 - 1 } January 1 & 13 & 36 & 5 & 2 \\
Reagan & 11 & 35 & 3 & 7 \\
Childhood Memories & & & & \\
\cline { 1 - 4 } Moon & 10 & 23 & 5 & 18 \\
School & 17 & 16 & 2 & 21 \\
Earliest Memory & 21 & 30 & 5 & 0 \\
\hline
\end{tabular}


Table 6

Correlations of Field Ratios

\begin{tabular}{lcc}
\hline & LEM Field Ratio & RED Field Ratio \\
\hline QMI & .104 & .064 \\
Barratt & .176 & .212 \\
Gordon & .180 & .173 \\
VVIQ & .137 & -.029 \\
VVQ & .174 & .102 \\
DAT & .244 & $.333 *$ \\
Cube & .197 & $.433 \dagger$ \\
School & .063 & .022 \\
Moon & .036 & -.080 \\
January I & -.069 & .020 \\
Reagan & -.032 & .058 \\
Mean Age $\ddagger$ & -.221 & -.135 \\
Earliest Age $\$$ & -.033 & -.044 \\
Memory Number & .000 & -.040 \\
\hline Note- $n=56 .{ }^{*} p<.01 ; \dagger p<.001 ; \ddagger n=49 ; \S n=52$.
\end{tabular}

tive as opposed to the observer perspective. For the five Recalled-Event Descriptions, the RED field ratio was the ratio of the number of field memories to the total number which received either type of rating [field/(observer + field)]. The LEM field ratio was similarly defined on the reports given in the List of Early Memories. The correlation between these two ratios was .61 ( $p<.001$, $\mathrm{n}=56$ ), indicating that the observer/field distinction is relatively stable over two types of memory tasks. The correlations between these two ratios and the other variables in our study are reported in Table 6 . All correlations are computed on a sample size of 56 except for those utilizing the variables Mean Age and Earliest Age, where the sample sizes were 49 and 52 respectively. The highest correlations are with the two spatial tasks, the DAT and the Cube. Those subjects who scored high on these mental spatial manipulation tasks also tended to have a higher percentage of field memories, that is, memories in which their perspective was the same as it had been in the original situation.

\section{DISCUSSION}

Our data confirm the distinction between reported vividness of mental imagery on the one hand and objectively measured spatial visualization on the other. In addition, we confirmed the existence of a third imagery dimension, spontaneous elaboration. The factors we have called vividness and control and spatial manipulation are familiar from the literature (DiVesta et al., 1971; Garro, 1982; Paivio, 1971; Richardson, 1977a). Spontaneous elaboration, however, has only been reported once before (Garro, 1982). This imagery dimension is represented by tasks that seem to assess the natural use of imagery. It is distinct from the vividness and control factor in that it does not assess an individual's ability to use imagery on demand, but rather, it assesses the tendency to use imagery spontaneously. It is also distinct from the spatial manipulation factor.
Not one of these three imagery dimensions is closely related to measures of reported childhood memory. Variables loading on the childhood memory factor seem to represent both the richness of memories (School and Moon) and the age at which they were established (Earliest Age and Mean Age). These four variables do not have high loadings on any of the imagery factors. The process of remembering instances from childhood seems to be independent of the forms of imagery investigated here. The conflict between these findings and those of Karis (1980) is somewhat puzzling. The differences may be procedural: Karis's measure of childhood memory was different from ours in that it included both specific and general memories. Moreover, the variable most strongly correlated with childhood memory in Karis's study was Slee's VES (1980), which was not used here. (Rooney, 1984, found that the VES has questionable reliability.) Nevertheless, the discrepancy between Karis's results and ours is substantial. One of his memory measures correlated .50 with the VVIQ, while none of our memory-VVIQ correlations was higher than 19.

The fact that some of our memory variables did not load strongly on any of the extracted factors probably can be explained in procedural terms. (1) Recent memories: Perhaps a quarter page is not enough to accommodate everything that is remembered from a recent event. This would impose a selection requirement on the "canonical categories" reported in Reagan and January 1, resulting in increased variability and low factor loadings. (2) Earliest memory: Since everyone has an earliest memory, the amount written about it may just reflect an individual's tendency to write a lot or a little. (This tendency may also affect Reagan and January 1 , if everyone recalls them.) The correlations between the number of words written about the first memory and the number written about the other recalled events support this interpretation. They are all positive $(.10, .17, .17, .30$, and .38), and the largest of them (with School) is significant at the .05 level after a Bonferroni correction for multiple comparisons. (3) Memory number: Even all three factors together accounted for less than $27 \%$ of the variance of memory number. Because subjects were only permitted 5 min to list their memories, speed of writing and of recollecting may account for much of the variance. Other researchers (e.g. Waldfogel, 1948) have allotted up to $85 \mathrm{~min}$ for similar tasks. The unreliability created in this way may explain why we failed to replicate Garro's (1982) correlation between imagery and early memory: she used a memory number measure.

Our exploratory analyses of the observer/field distinction support the reports of Henri and Henri (1896): more observer perspectives were associated with reported childhood memories than with recent memories. In addition, there was a significant positive correlation between spatial ability and the tendency to take the field perspective. If we assume that more effective visualizers have visually 
richer and more detailed memories, these two findings seem entirely compatible. Relatively more recent or more detailed visual memories may be less likely to shift from the field to the observer perspective than older or less detailed ones.

\section{REFERENCES}

BarRatt, P. E. (1953). Imagery and thinking. Australian Journal of Psychology, 5, 154-164.

Bennett, G. K., Seashore, H. G., \& Wesman, A. G. (1947). Differential Aptitude Test: Space Relations, Form T. New York: The Psychological Corporation.

Brown, R., \& Kulik, J. (1977). Flashbulb memories. Cognition, 5, 73-99.

DiVesta, F. J., Ingersoll, G., \& Sunshine, P. (1971). A factor analysis of imagery tests. Journal of Verbal Learning \& Verbal Behavior, 10, $471-479$.

GARRO, L. C. (1982). Imagery's role in cognition. Unpublished doctoral dissertation, Duke University, Durham, NC

GoRDON, R. (1949). An investigation into some of the factors that favor the formation of stereotyped images. British Journal of Psychology, 39, 156-167.

Henri, V., \& Henri, C. (1896). Enquete sur les premier souvenirs de l'enfance. L'Annee Psychologique, 3, 184-198.

JuHASZ, J. B. (1972). On the reliability of two measures of imagery. Perceptual \& Motor Skills, 35, 874.

KARIS, D. (1980). Individual differences in autobiographical memory. Unpublished doctoral dissertation, Cornell University, Ithaca, NY.

Likert, R. \& Quasha, W. H. (1948). Revised Minnesota Paper Form Board Test. New York: Psychological Corporation.
MaRKS, D. F. (1973). Visual imagery differences in the recall of pictures. British Journal of Psychology, 64, 17-24.

McKelvie, S. J. \& GRINGRas, P. P. (1974). Reliability of two measures of visual imagery. Perceptual \& Motor Skills, 39, 417-418.

Nigro, G., \& Neisser, U. (1983). Point of view in personal memories Cognitive Psychology, 15, 467-482.

PaIvio, A. (1971). Imagery and verbal processes. New York: Holt, Rinehart \& Winston.

Richardson, A. (I969). Mental imagery. London: Routledge \& Kegan Paul.

Richardson, A. (1977a). The meaning and measurement of memory imagery. British Journal of Psychology, 68, 29-43.

RICHARDSON, A. (1977b). Verbalizer-visualizer: A cognitive dimension. Journal of Mental lmagery, 1, 109-126.

ROONEY, P. (1984). Individual differences in imagery and their relation to visual memory. Unpublished doctoral dissertation: Cornell University, Ithaca, NY.

SheEhan, P. W. (1967). A shortened form of Betts' Questionnaire Upon Mental Imagery. Journal of Clinical Psychology, 23, 386-389.

SLEE, J. A. (1980). Individual differences in visual imagery ability and the retrieval of visual appearances. Journal of Mental Imagery, 4 , 93-113.

THORNDIKE, R. M. (1978). Correlational procedures for research. New York: Gardner Press.

WALDFOGEL, S. (1948). The frequency and affective character of childhood memories. Psychological Monographs: General \& Applied, 62 (4. Whole No. 291).

(Manuscript received November 6, 1984: revision accepted for publication December 7, 1985.) 